\title{
Pielonefritis y embarazo. Experiencia durante un año en un hospital general
}

\author{
N. PAZOS OTERO, L. FUENTES RICOY, B. FERRÁNDEZ PÉREZ, C. MARTÍNEZ \\ VÁZQUEZ, M. MARTÍNEZ POCH ${ }^{1}$, J. L. OSUNA DÍAZ ${ }^{1}$

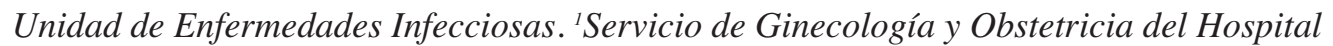 \\ Xeral Cíes. Complejo Hospitalario de Vigo. Vigo (Pontecedra). Universidad de Santiago \\ de Compostela
}

\section{RESUMEN}

Objetivos: La incidencia de la pielonefritis durante el embarazo alcanza hasta un $2 \%$. Para prevenirla recomendamos realizar análisis de orina en el primer trimestre con el objeto de detectar bacteriuria asintomática, debiéndose tratar aquellos casos con urocultivo positivo.

Métodos: Se recogen de forma retrospectiva todos los casos diagnosticados de pielonefritis aguda en embarazadas ingresadas en nuestro Centro a lo largo del año 2004 y se tabulan los datos demográficos, métodos diagnósticos, tratamientos, evolución, nuevos episodios y repercusiones sobre la fecha del parto y del recién nacido.

Resultados: Estudiamos todos los casos de pielonefritis en embarazadas ocurridas en nuestro centro durante un año (4.700 partos). Objetivamos que el despistaje de bacteriuria se hacía, de manera incorrecta con sedimento urinario (piuria). La incidencia fue de $0,21 \%$, atribuyendo dicha cifra tan baja a que, posiblemente, alguna enferma con pielonefritis no ingresó en nuestro centro. Las evoluciones fueron favorables, siendo el único germen aislado E. coli. Las pielonefritis del primer trismestre recidivaron.

Conclusiones: En todos los embarazos se debe realizar urocultivo en el primer trimestre debiendo, después del tratmiento adecuado, repetir el urocultivo, sobre todo si la bacteriuria ocurre en el primer trimestre de embarazo.

PALABRAS CLAVE: Pielonefritis. Embarazo.
PYELONEPHRITIS AND PREGNANCY. OUR EXPERIENCE IN A GENERAL HOSPITAL

\begin{abstract}
Objetive: The incidence of pyelonephritis during pregnancy reaches $2 \%$. We recommend obtaining a urinalysis during the first trimester in order to detect asymptomatic bacteriuria and treat those cases with positive urine culture.

Methods: We restrospectively reviewed all cases diagnosed as acute pyelonephritis in pregnant women admitted to our hospital during 2004 and analyzed demographic data, diagnostic methods, treatments, outcome, new episodes and the impact on the date of birth and the newborn.

Results: We studied all the cases of pyelonephritis in pregnant women diagnosed in our hospital for one year $(4,700$ childbirths). We found that screening of bacteriuria was done incorrectly based on the presence of pyuria in the sediment of urine specimen. The incidence was $0.21 \%$, and such a low rate might be related to the possibility that some patients were not admitted in our hospital. Prognosis was excellent being E. coli the only agent isolated in all cases. Pyelonephritis that occurred during the first trimester relapsed.

Conclusions: A urine culture must be obtained during the first trimester of pregnancy and should be repeated after completion of adequate therapy of an infection, particulary if bacteriuria is detected in the first trimester.
\end{abstract}

KEY WORDS: Pyelonephritis. Pregnancy.

Pazos Otero N, Fuentes Ricoy L, Ferrández Pérez B, Martínez Vázquez C, Martínez Poch M, Osuna Díaz. JL. Pielonefritis y embarazo. Experiencia durante un año en un hospital general. An Med Interna (Madrid) 2007; 24: 585-587.

\section{INTRODUCCIÓN}

Se sabe desde hace años que la bacteriuria asintomática es frecuente en embarazos (1-4) y que un alto porcentaje de estos, que puede alcanzar un 20-40\%, desarrollan pielonefritis si no son manejados adecuadamente (5-8). Por otro lado, hay evidencias que demuestran que las pacientes con bacteriuria asintomática presentan una mayor incidencia de partos prematuros y bajo peso al nacimiento (9-10). Todo esto ha llevado a recomendar, de forma unánime, la identificación de bacteriuria en el primer trimestre del embarazo, seguida de tratamiento antibiótico adecuado (11-13).

De todas maneras, sigue existiendo controversia acerca de la duración óptima del tratamiento, tanto del primer epi- sodio como de las recurrencias (14-16), de la conveniencia de repetir el urocultivo si la primera determinación es negativa $(4,13)$ y de si se puede utilizar el sedimento urinario como primera aproximación diagnóstica a estos pacientes (16-18).

Nuestro hospital es referencia de Obstetricia para una población de 500.000 habitantes, controlándose a todas las embarazadas desde el primer trimestre hasta el puerperio. Al estar embarazada, ante cualquier manifestación clínica, son valoradas en Obstetricia, ingresándose los casos de pielonefritis en dicho servicio, al margen de que se realicen con posterioridad las consultas pertinentes.

Interesados por este tema, analizamos todos los casos de pielonefritis agudas acontecidos en embarazadas e ingresadas

Trabajo aceptado: 10 de julio de 2007 
en nuestro centro a lo largo de un año, tabulando los datos más relevantes, contrastándolos con los descritos en la literatura.

\section{PACIENTES Y MÉTODOS}

Se recogen de forma retrospectiva todos los casos diagnosticados de pielonefritis aguda en embarazadas, ingresadas en nuestro Centro a lo largo del año 2004 para ello se utiliza el sistema informatizado de codificación de altas. Definimos pielonefritis aguda a todo proceso febril con dolor en fosa lumbar espontáneo o a la percusión asociado a infección aguda del tracto urinario con disuria, polaquiuria o dolor suprapúbico (19). Se tabulan los datos demográficos, embarazos previos, pielonefritis en embarazos previos, mes del embarazo en que se produce, análisis previos a la pielonefritis, resultado de sedimento urinario, urocultivo y hemocultivos durante la pielonefritis, resultado de pruebas de imagen, tratamiento antibiótico realizado, evolución y nuevos episodios de pielonefritis y repercusiones sobre fecha de parto y del recién nacido.

\section{RESULTADOS}

Durante el año 2004 se ingresaron en nuestro centro diez pielonefritis agudas en embarazadas, atendiéndose en este centro a 4.700 partos, lo cual supone que un $0,21 \%$ de embarazadas fueron diagnosticadas de pielonefritis. No podemos asegurar que alguna pielonefritis fuese tratada ambulatoriamente o en otro centro pero, dado el manejo conservador que se realiza en embarazadas, no parecería probable.

Las edades de las pacientes oscilaron entre 19 y 40 años, con una media de 27,5 años. Ocho eran primíparas y dos habían tenido un único embarazo previo. De estas dos multíparas, en una de ellas se recogía el antecedente de pielonefritis en su anterior embarazo. Dos pacientes presentaron su pielonefritis en el primer trimestre, una en el segundo y las siete restantes en el tercer trimestre de embarazo.

A todas las pacientes se les había realizado previamente a su pielonefritis, en el primer trimestre, un sedimento urinario y no urocultivo, al estar protocolizado en el Servicio de Obstreticia hacer sólo urocultivo a aquellas pacientes embarazadas con sedimento patológico. En ninguna de ellas este sedimento urinario previo había resultado patológico y, por lo tanto, antes de su pielonefritis no se había realizado urocultivo. Los urocultivos fueron positivos para E. coli en siete pacientes y negativos en los tres a los que se les había administrado, con anterioridad a la recogida de la muestra de orina, tratamiento antibiótico. En tres muestras el germen fue sensible a ampicilina y los restantes sensibles a cefuroxima y fosfomicina. Sólo una paciente presentó hemocultivo positivo a E.coli con un fenotipo similar al del germen aislado en orina. Se realizaron pruebas de imagen en ocho pacientes, consistentes en ecografía renal que demostró ectasia de las vías urinarias en siete y Resonancia Nuclear Magnética en una que demostró microabscesos en el riñón izquierdo; después de las pruebas de imagen no se cambió ninguna actitud terapéutica previa. Todas las pacientes fueron tratadas en un principio con antibioterapia parenteral, seguida de vía oral, manteniéndose un total de dos semanas el tratamiento. Cuatro pacientes fueron tratadas en un principio con ceftriaxona endovenoso seguido de cefuroxima oral, cinco únicamente con cefuroxima y una desde el principio con fosfomicina. Una paciente desarrolló shock séptico por lo que fue trasladada a la UCI, el resto de las pacientes fueron atendidas en la planta de Obstreticia, evolucionando todas (incluida la paciente con shock séptico) de forma favorable. En cuanto al seguimiento, una paciente se cambió de residencia por lo que no se puede saber cómo evolucionó; de las restantes, las dos pacientes que presentaron su pielonefritis durante el primer trimestre volvieron a presentar pielonefritis en el segundo trimestre y una de estas otro episodio en el tercer trimestre. Los nueve partos a los que se asistió fueron a término, tres de ellos por cesárea, no recogiéndose bajo peso en los recién nacidos ni ninguna otra alteración.

\section{DISCUSIÓN}

La incidencia de pielonefritis en embarazadas alcanza el 0,5-1\%, por lo es obligado el despistaje mediante la realización de un urocultivo en el primer trimestre del embarazo, debiéndose tratar los casos que resultan positivos (11-12,20).

Constatamos en nuestra revisión, que el protocolo en nuestro Servicio de Obstreticia utiliza como primera aproximación diagnóstica un sedimento urinario. En este sentido, estudios comparativos demuestran que la piuria identifica sólo un 50\% de las bacteriurias en embarazadas (16), siendo el test apropiado el urocultivo $(17,18,21)$. Nuestra baja incidencia $(0,21 \%)$ podría estar en relación a que alguna paciente es ingresada en otro centro o tratada ambulatoriamente, dado que para los problemas no obstétricos son atendidas en otros hospitales. Se ha cambiado el protocolo, utilizándose en la actualidad directamente los urocultivos con la esperanza de objetivar una caída sustancial de pielonefritis en estas pacientes.

Otro tema controvertido es cuánto tiempo debe mantenerse el tratamiento antibiótico en estas pacientes (13). Las pacientes en nuestra serie que presentaron el episodio de pielonefritis en el tercer trimestre no presentaron recidiva pero las dos que la presentaron en el primero sí. En un trabajo prospectivo y randomizado en el que se trata por un lado a un grupo de pacientes con bacteriuria durante todo el embarazo y otro grupo en el que se trata sólo durante 14 días, repitiéndose

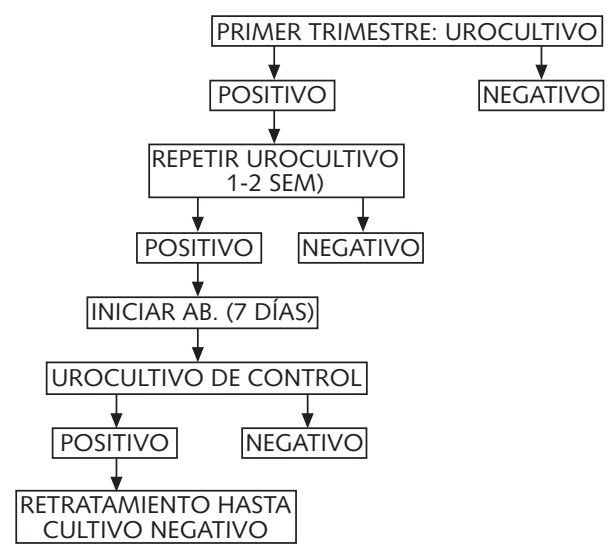

Fig. 1. Algoritmo para prevenir pielonefritis en embarazadas de la IDSA. 
el urocultivo a la semana y con retratamiento si existe recurrencia, no es capaz de demostrar distintas evoluciones en cuanto a recidivas o reinfecciones (14). Otra revisión reciente concluye que no hay suficientes evidencias para recomendar un régimen terapéutico concreto en estas situaciones (15). La guía de la Sociedad Americana de Enfermedades Infecciosas (IDSA) recomienda urocultivos periódicos después del tratamiento (13). En nuestra experiencia, las infecciones urinarias en el tercer trimestre no necesitan de más controles, no así las del primero a las que se les debe repetir el urocultivo ante la posibilidad de recidiva.

La evolución, hallazgos radiológicos, germen aislado y antibiograma no nos permiten apreciar diferencias sustancia-

\section{Bibliografía}

1. Kincaid-Smith P, Bullus M. Bacteriuria in pregnancy. Lancet 1965; 1 : 395-9.

2. Whalley PJ. Bacteriuria of pregnancy. Am J Obst Gynecol 1967; 97: 723-8

3. Fátima $\mathrm{N}$, Ishrats. Frecuency and risk factors of asintomatic bacteriuria during pregnancy. J Coll Physicians Surg Pak 2006; 16: 273-5.

4. Stenqvist K, Dahlen-Nilsson I, Lidin-Janson G, et al. Bacteriuria in pregnancy. Frecuency and risk of adquisition. Am J Epidemiol. 1989; 129: 372-9

5. Kass EH. Pyelonephritis and bacteriuria. A major problem in preventive medicine. Ann Intern Med 1962; 56: 46-53.

6. Little PJ., The incidence of urinary tract infection in 5,000 pregnant women. Lancet 1966; 2: 925-8.

7. Pathak UN, Tang LL, Williams LL, Stuart KL. Bacteriuria of pregnancy: Results of treatment. J Infect Dis 1969; 120: 91-103.

8. Smaill F. Asymptomatic bacteriuria in pregnancy. Best Pract Res Clin Obstet Gynaecol 2007; 21: 439-50.

9. Mittendorf R, Willians MA, Kass E.S. Prevention of preterm delivery and low birth weight associated with asyntomatic bacteriuria. Clin Infect Dis 1992; 14: 927-32

10. Romero R, Oxarzun E, Mazor M, Sirtori M, Hobbins JC, Bracken M. Meta-analysis of the relationship betwen asintomático bacteriuria and preterm delivery/low birth weight. Obstet Gynecol 1989; 73: 576-82.

11. Gratacos E, Torres PJ, Vila J, Alonso PL, Cararach V. Screening and treatment of asintomatic bacteriuria in pregnancy prevent-pyelonephritis. J Infect Dis 1994; 169: 1392-930. les con pielonefritis en otros grupos, al contrario de lo que se había descrito clásicamente (6), si bien condicionaron gastos y molestias importantes, obligando a ingresar en la UCI a una paciente. Por otro lado, aunque nuestro estudio no está diseñado para sacar ninguna conclusión en este sentido, tampoco apreciamos alteración alguna en nuestro grupo de afectadas en lo que respecta a parto prematuro o bajo peso del recién nacido, como parece apreciarse en trabajos que comparan a grupos tratados y no tratados (9-10).

Creemos que es imprescindible seguir el algoritmo de la IDSA (Fig. 1) (13) para embarazadas, realizando directamente urocultivos en el primer trimestre para conseguir disminuir nuestra tasa de pielonefritis del embarazo.
12. Uncu Y, Uncus G, Esmer A, Bilgel N. Should asyntomatic bacteriuria be screened in pregnancy? Clin Exp Obstet Gynecol 2002; 29: 185-281.

13. Nicolle LE, Bradley S, Colgan R, Rice JC, Schaefer A, Hooton TM. Infectious Disease Society of Aerica guidelines for the diagnosis and treatment of asyntomatic bacteriuria in adults. Clin Infect Dis 2005; 40: 643-54.

14. Whalley PJ, Cunninghan F.G. Short-term versus continuous antimicrobial therapy for asyntomatic bacteriuria in pregnancy. Obstet Gynecol 1977; 49: 262-5.

15. Villar J, Lydon-Rochelle MT, Gulmezoglu AM, Roganti A. Duration of treatment for treatment for asymptomatic bacteriuria during pregnancy. Cochrane Database. Syst Rev 2002; 2: CD000491

16. Bachman JW, Heise RH, Naessons JM, Timmerman MG. A study of various test to detect asyntomatic urinary tract infections in a obstetric population. JAMA 1993; 270: 1970-4.

17. Herraiz MA, Hernández A, Asenjo E, Herraiz I. Urinary tract infection in pregnancy. Enferm. Infecc Microbiol Clin 2005; 23 (Supl. 4): 40-6.

18. Kacmaz B, Cakir O, Aksoy A, Biri A. Evaluation of rapid urine screening test to detect asymptomatic bacteriuria in pregnancy. Jpn J Infect Dis 2006; 59: 261-3.

19. Hooton TM, Stamm W.E. Diagnosis and treatment of uncomplicated urinary tract infection. Infect Dis Clin North Am 1997; 11: 551-82.

20. Smaill F., Antibiotic for asy ntomatic bacteriuria in pregnancy .Cochrane Database Syst Rev 2001; 2: CD000490.

21. The US Preventive ServicesTask Force. Screening for asyntomatic bacteriuria, hematuria and proteinuria. Am Fam Physician 1990; 42: 389-95. 